\title{
Sutura palatina mediana: avaliação do grau de ossificação em crânios humanos*
}

\author{
Jussara ENNES**, Alberto CONSOLARO***
}

\begin{abstract}
Resumo
Objetivos: Avaliar o grau de ossificação da sutura palatina mediana em crânios humanos de diferentes grupos etários. Amostra: Crânios humanos (28) divididos em quatro grupos de acordo com a fase do desenvolvimento cronológico: crianças, adultos jovens, adultos e idosos. Material: Radiografias Oclusais Totais da Maxila dos crânios dos diferentes grupos (28). Imagens digitalizadas das Radiografias Oclusais Totais da Maxila (28). Métodos: A presença de pontes de ossificação na sutura palatina mediana foi identificada macroscópica e estereomicroscopicamente, registrada e quantificada. Os crânios foram radiografados pela Técnica Oclusal total da Maxila, com modificação na posição do filme, no eixo horizontal. As imagens radiográficas obtidas foram digitalizadas e submetidas à variação de tons claros e escuros e ao ajuste de contraste e brilho para a investigação do grau de ossificação da sutura palatina mediana. Conclusão: Concluiu-se que a ossificação da sutura palatina mediana inicia-se principalmente na fase adulta e no segmento posterior. A técnica Radiográfica Oclusal Total da Maxila não proporciona imagem adequada à identificação do grau de ossificação na sutura palatina mediana.
\end{abstract}

Palavras-chave: Sutura palatina mediana. Expansão rápida da maxila. Disjunção intermaxilar. Radiografia oclusal total da maxila.

Durante o planejamento do tratamento ortodôntico e ortopédico dentofacial, pode-se necessitar da expansão transversal das medidas do terço médio da face para a obtenção de uma relação funcional e estética equilibrada e harmônica entre os dentes e entre os maxilares, no contexto da face. Quando se identifica esta necessidade, a indicação de tratamento pode ser a Expansão Rápida da Maxila ${ }^{1,4,9,10,11}$.

Idades mais avançadas dos pacientes sempre foram consideradas como fator limitante no pla- nejamento desses casos, pois se acreditava ocorrer ossificação na sutura palatina mediana e maior rigidez do arcabouço esquelético da face. Nesses casos, poderia se optar por intervir cirurgicamente nesta estrutura com a finalidade de expandir a maxila ${ }^{3,14}$.

$\mathrm{Na}$ prática clínica, a radiografia Oclusal Total da Maxila tem sido utilizada como meio de diagnóstico quanto ao grau de ossificação da sutura palatina mediana, na fase do planejamento ortodôntico.

A efetividade da imagem proporcionada pela

* Parte da tese apresentada ao Curso de Pós-Graduação em Odontologia - Doutorado em Patologia Bucal da Faculdade de Odontolgia de Bauru -USP

** Professora Adjunta Doutora da Disciplina de Anatomia Odontológica da Universidade Federal de Mato Grosso do Sul - UFMS.

*** Professor Titular da Disciplina de Patologia Bucal da Faculdade de Odontologia de Bauru - USP. 
radiografia Oclusal Total da Maxila para identificação do grau de ossificação na sutura palatina mediana não havia sido metodologicamente determinada. Este trabalho proporcionou a análise comparativa do grau de ossificação identificado macroscópica e estereomicroscopicamente na sutura palatina mediana em crânios humanos com as análises da imagem radiográfica da sutura obtida pela técnica Oclusal Total da Maxila.

\section{MATERIAL E MÉTODOS}

Foram avaliados 28 crânios de Homo sapiens (homem) em diferentes fases do desenvolvimento cronológico (Tab. 1), provenientes da coleção da Disciplina de Patologia Bucal da FOB-USP, sob os critérios de análise macroscópica, estereomicroscópica e radiográfica. Os crânios foram classificados quanto à idade cronológica pela análise da dentadura, segundo critérios descritos por Gustafson ${ }^{8}$. O desgaste da superfície oclusal, periodontose, deposi-

\begin{tabular}{|c|c|c|c|}
\hline Criança & Adulto jovem & Adulto & Idoso \\
\hline $\mathrm{H}-1.1$ & H-2.1 & H-3.1 & H-4.1 \\
\hline$H-1.2$ & $\mathrm{H}-2.2$ & H-3.2 & $\mathrm{H}-4.2$ \\
\hline $\mathrm{H}-1.3$ & $\mathrm{H}-2.3$ & H-3.3 & $\mathrm{H}-4.3$ \\
\hline- & - & H-3.4 & H-4.4 \\
\hline- & - & H-3.5 & H-4.5 \\
\hline- & - & H-3.6 & H-4.6 \\
\hline- & - & H-3.7 & H-4.7 \\
\hline- & - & H-3.8 & H-4.8 \\
\hline- & - & H-3.9 & H-4.9 \\
\hline - & - & H-3.10 & - \\
\hline - & - & H-3.11 & - \\
\hline- & - & H-3.12 & - \\
\hline- & - & $\mathrm{H}-3.13$ & - \\
\hline
\end{tabular}

ção de dentina secundária no interior da cavidade pulpar, transparência do ápice pulpar e deposição de cemento na raiz foram analisados e pontos de 0 a 4 foram aferidos quanto a cada um destes critérios. $\mathrm{O}$ somatório dos pontos de cada crânio foi lançado em uma reta de regressão, construída pelo autor ${ }^{8}$, onde se obtinha a idade do crânio. $\mathrm{Na}$ ordenada dispunham-se os valores dos somatórios dos escores, e na abscissa, a idade em décadas. A projeção do somatório de pontos obtido do crânio na reta de regressão determinava a idade do crânio (Fig. 1).

A fase do desenvolvimento cronológico foi assim determinada: criança, adulto jovem, adulto e idoso, observando-se o ciclo vital da espécie.

Para definição destas fases foram aplicados os conceitos $^{2}$ :

- criança: indivíduo que não atingiu a puberdade (0 a 12 anos);

- adulto jovem (púbere): indivíduo na fase entre a infância e a maturidade (13 a 18 anos);

- adulto: indivíduo que atingiu pleno vigor e tamanho, bem como capacidade de reprodução e de cuidar dos assuntos pessoais (19 a 60 anos);

- idoso: aquele que atingiu a senescência.

$\mathrm{Na}$ análise macroscópica, observou-se o aspecto das margens ósseas da sutura palatina mediana, descrevendo-o textualmente. Realizou-se ainda, uma classificação quanto ao grau de ossificação. A localização e extensão de pontes foram registrados no desenho, compreendendo as três regiões da sutura palatina mediana como se observa na figura 2 . A extensão de cada ponte foi medida no desenho esquemático com régua milimetrada.

Escores crescentes foram atribuídos, determinados pela presença e extensão das pontes de ossificação, sendo os graus: 0, 1, 2 e 3, conforme ilustra a figura 3 .

- grau 0: correspondendo à ausência de pontes de ossificação;

- grau 1: presença de pontes com extensão entre 1 a $3 \mathrm{~mm}$;

- grau 2: presença de pontes com extensão entre 3,1 a $6 \mathrm{~mm} \mathrm{e}$,

- grau 3: presença de pontes com extensão 


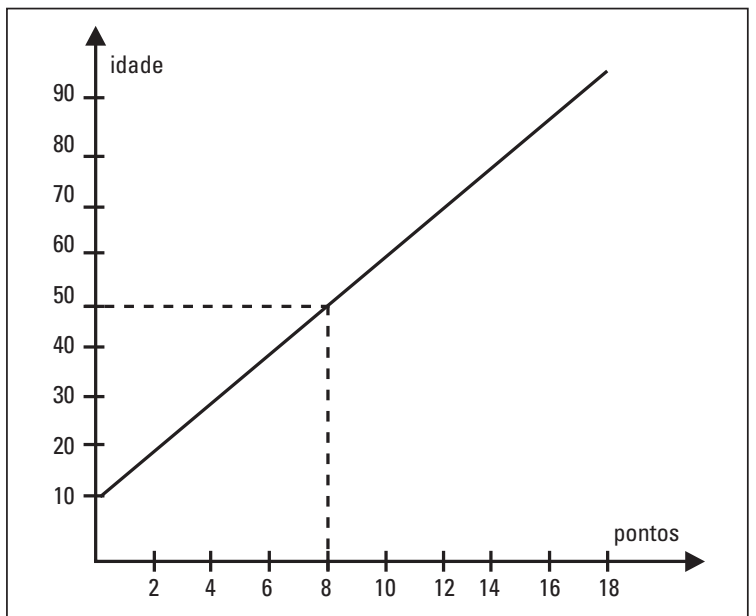

FIGURA 1 - Reta de regressão utilizada para obtenção da idade cronológica de um indivíduo a partir de valor obtido por somatória dos escores atribuídos segundo os aspectos dentários em crânios de homens ${ }^{8}$. No exemplo, 8 pontos equivalem à idade cronológica de 50 anos.

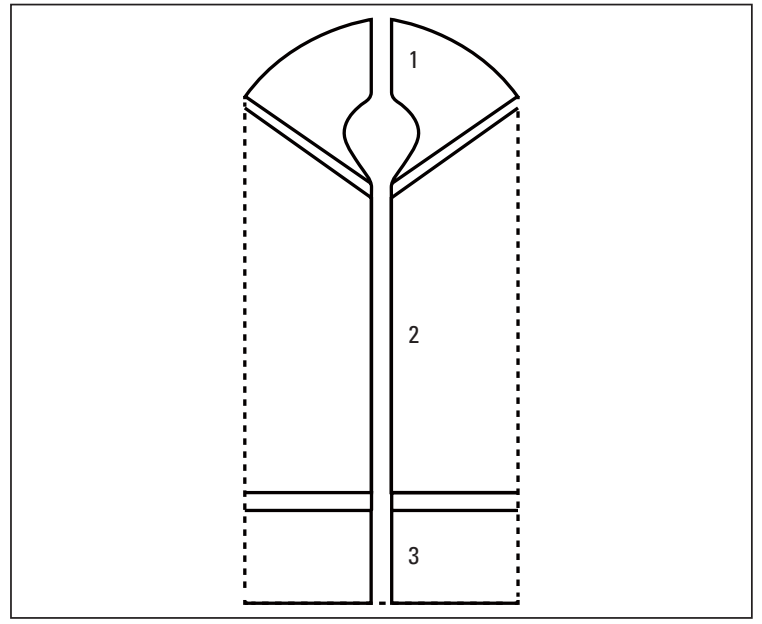

FIGURA 2 - Desenho esquemático para registro das pontes de ossificação presentes no trajeto da sutura palatina mediana em crânio de homem: 1) segmento anterior; 2) segmento palatino médio; 3) segmento palatino posterior.
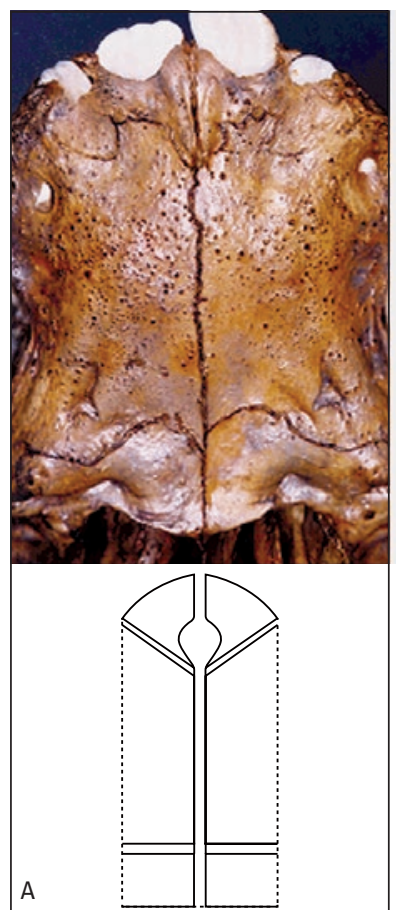

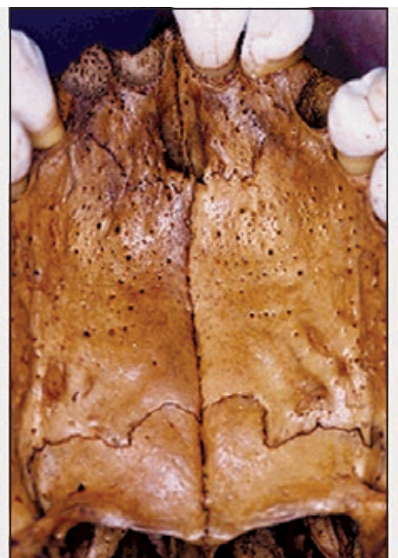

B
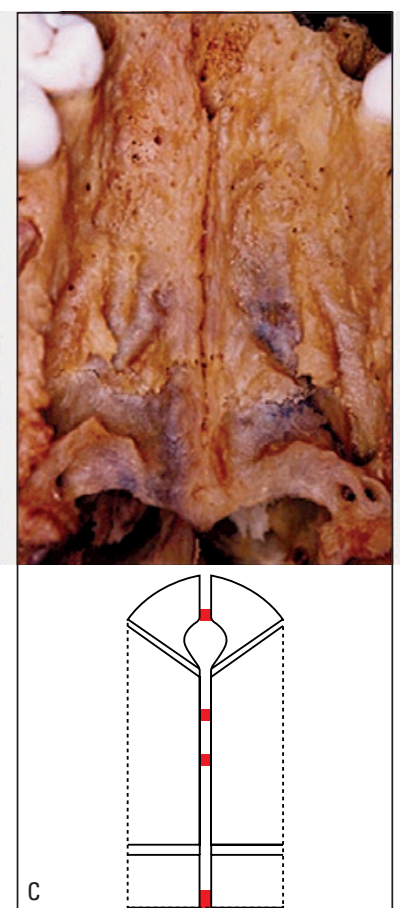
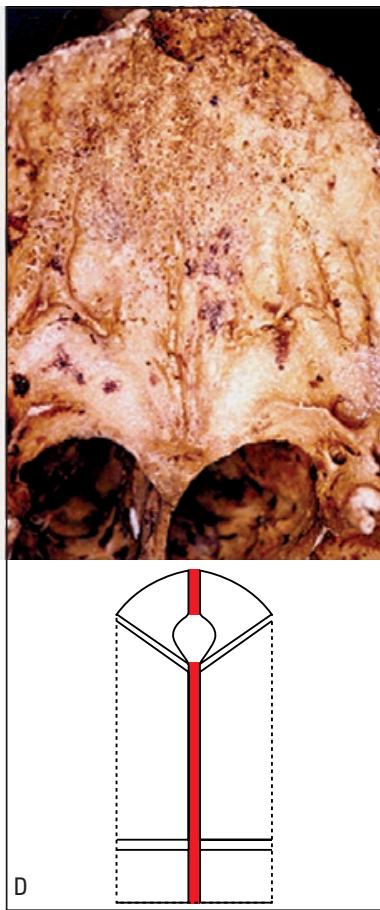

FIGURA 3 - Aspectos macroscópicos da sutura palatina mediana em crânios de criança com grau zero de ossificação na sutura (A), adulto jovem, com grau 1 (B) adulto, com grau 2 (C) e idoso, com grau 3 (D) e os respectivos desenhos esquemáticos para registro das pontes de ossificação presentes no trajeto da sutura.

acima de $6,1 \mathrm{~mm}$.

A análise estereomicroscópica dos crânios foi realizada com estereomicroscópio Stemi SV11APO (Zeiss - Alemanha), com iluminação direta proporcionada por foco de luz (Leitz Wetzlar Alemanha). Os critérios de análise foram os mes- mos utilizados para a análise macroscópica. Com o crânio posicionado sob as objetivas, as pontes de ossificação na sutura palatina mediana foram identificadas e registradas no desenho esquemático, como refinamento à análise macroscópica, confirmando a presença e extensão das pontes de 
ossificação, previamente identificados na análise macroscópica, sem divergências.

Para o desenvolvimento da técnica radiográfica, os crânios foram posicionados sobre filme radiográfico apoiado sob os elementos dentários ou rebordo alveolar com rotação de $90^{\circ}$ do filme, no plano horizontal ${ }^{6}$. Esta rotação permitiu a inclusão da sutura em sua total extensão antero-posterior.

Os crânios foram radiografados pela técnica Oclusal Total da Maxila, tomando a glabela como ponto de referência. A distância foco-filme foi de $20 \mathrm{~cm}$, o tempo de exposição foi 32s.

A produção das imagens para análise procedeu-se, inicialmente, com a digitalização das imagens radiográficas em resolução de 300 dpi. Posteriormente, as imagens armazenadas em for-
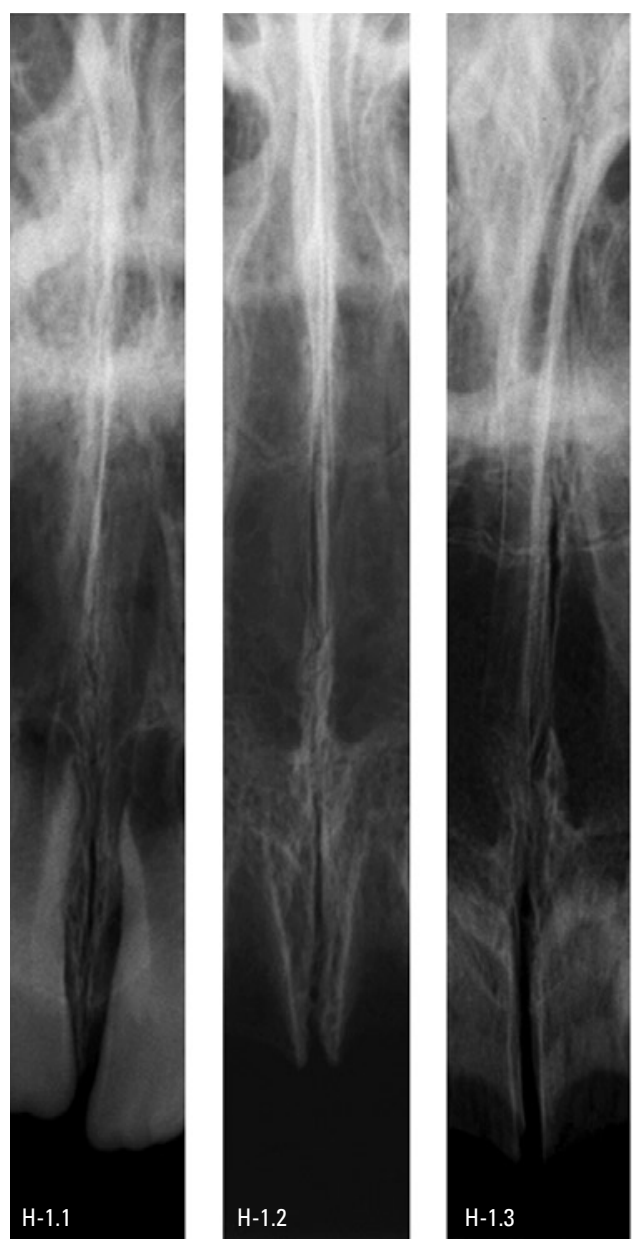

FIGURA 4 - Aspectos radiográficos da sutura palatina mediana de crânios humanos do grupo de crianças (H-1) e adultos jovens (H-2).

mato "TIFF", foram convertidas para tons de zinza, submetidas à variação de intensidade de tons escuros e claros e ao ajuste do contraste e brilho no programa "Adobe Photoshop - 6.0". utilizando-se programa "Power Point" e ampliadas proporcionalmente até a quase totalidade da área de apresentação na tela e cortadas em sua altura, para remover partes desnecessárias à análise, e em lateralidade, até se obter uma imagem com cerca de $0,5 \mathrm{~cm}$ de cada lado da sutura palatina mediana, destacadas por uma moldura linear branca e identificadas. As imagens da sutura palatina mediana resultaram em três apresentações: a primeira das imagens da sutura de crianças e adultos jovens, a segunda de adultos e a terceira de idosos (Fig. 4, 5, 6).
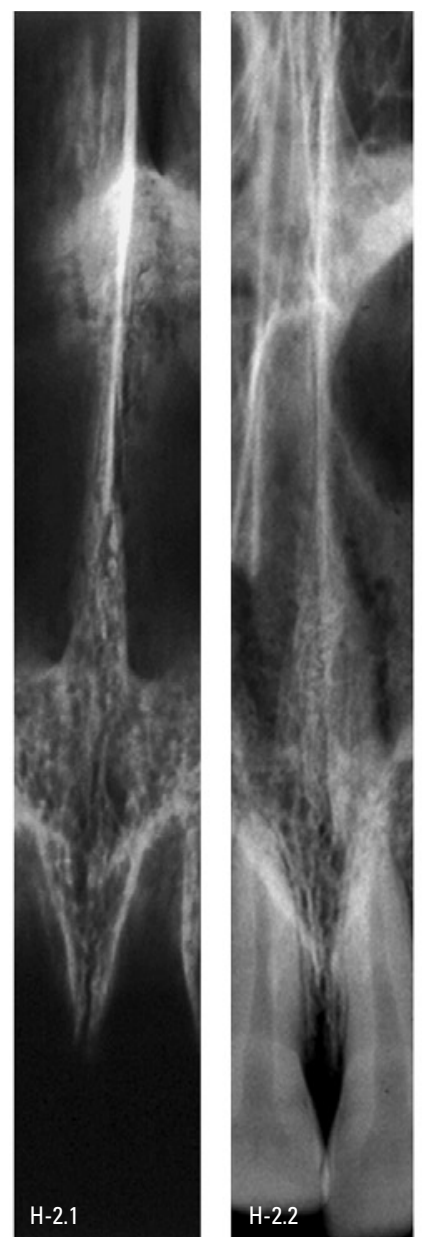

H-2.3

As imagens foram inseridas na apresentação

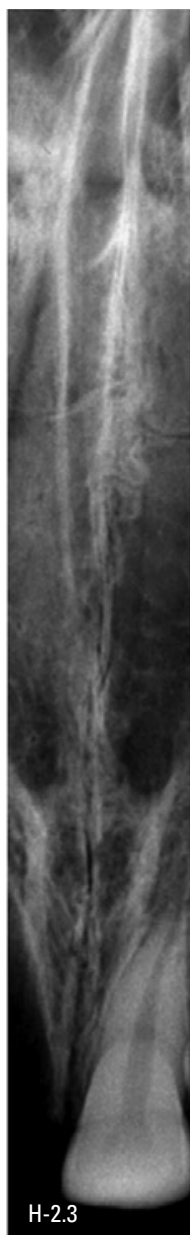



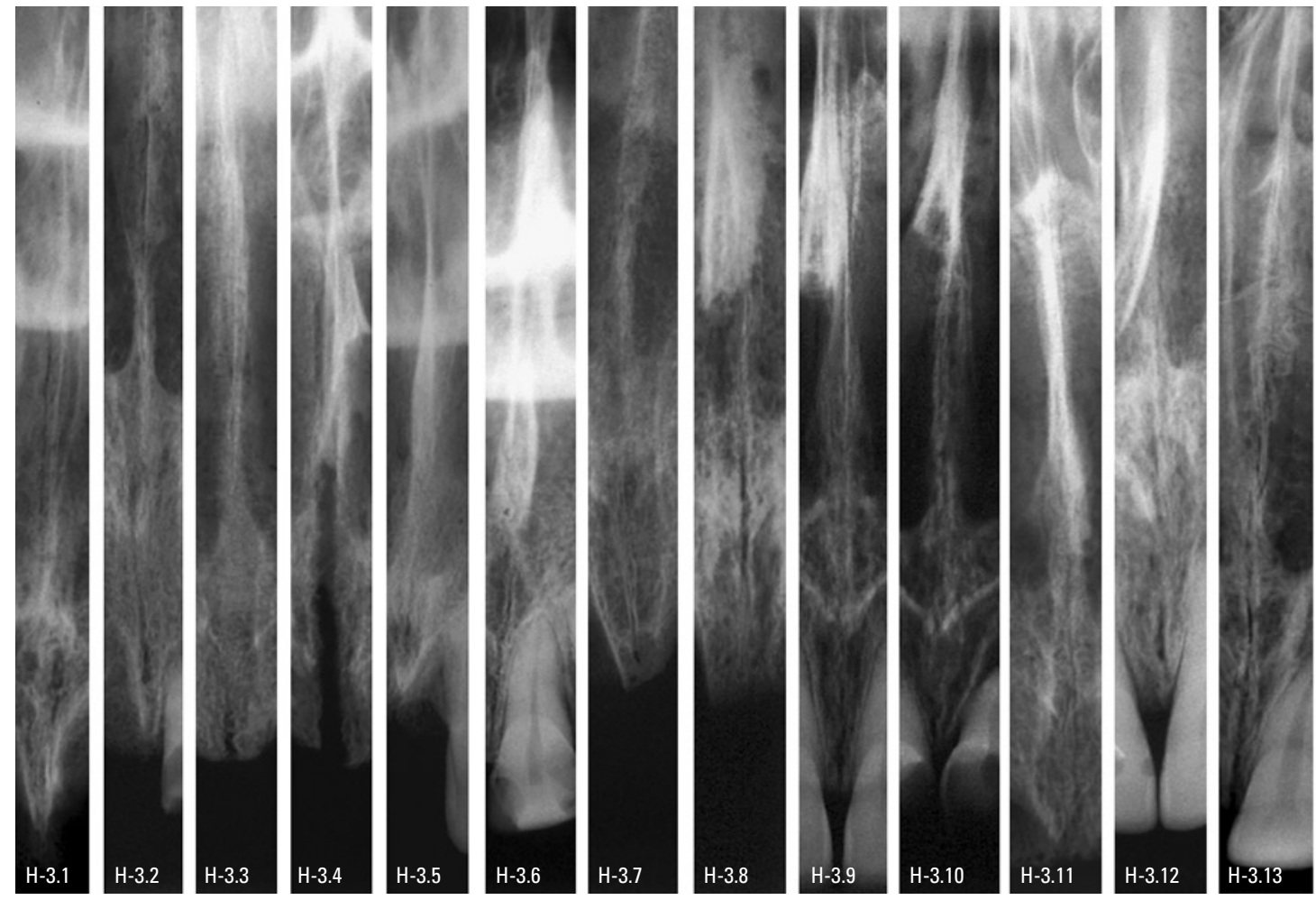

FIGURA 5 - Aspectos radiográficos da sutura palatina mediana de crânios humanos do grupo de adultos (H-3).
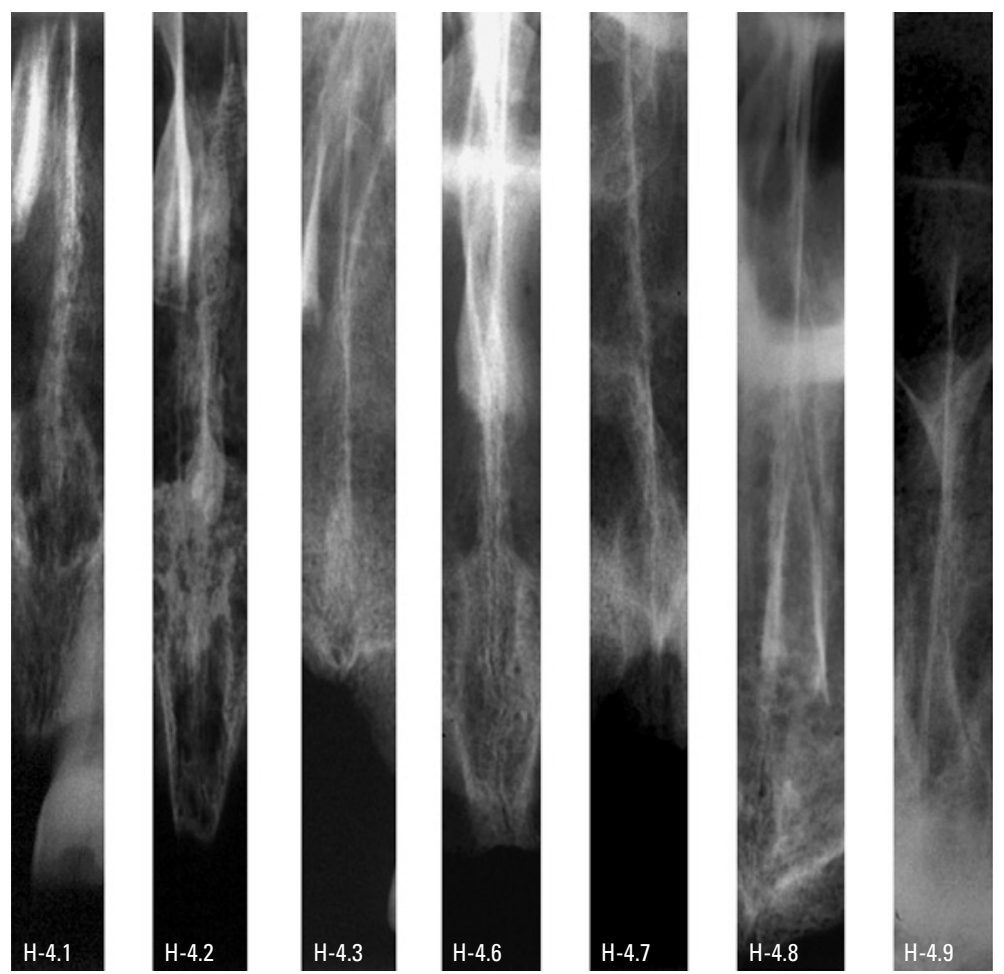

FIGURA 6 - Aspectos radiográficos da sutura palatina mediana de crânios humanos do grupo de idosos (H-4). 
A análise das imagens radiográficas digitalizadas da sutura palatina mediana foi realizada de forma descritiva com a projeção das imagens radiográficas oclusais em sala escura, por um projetor multimídia.

Os critérios utilizados para descrição da imagem radiográfica da sutura palatina mediana foram: presença de espaço entre as margens ósseas, radiopacidade e sinuosidade das margens ósseas. O registro da análise das imagens radiográficas digitalizadas foi descritivo e realizado por observador único.

\section{RESULTADOS}

\section{Quanto à ossificação}

As pontes de ossificação foram identificadas macroscopicamente nos exemplares dos grupos de adultos jovens, adultos e idosos. A ossificação do terço posterior da sutura foi mais freqüente. $\mathrm{O}$ grau de ossificação na sutura, atribuído em escores, pode ser observado nas tabelas 2, 3, 4 e 5 .

Nos crânios do grupo de crianças, não foram identificadas pontes de ossificação.

A imagem radiográfica da sutura palatina me- diana obtida dos crânios permitiu análise descritiva. As imagens radiográficas provenientes dos crânios de crianças permitiram constatar a presença de espaço radiolúcido linear estreito entre as margens ósseas da sutura palatina mediana no segmento anterior e/ou palatino médio. No sentido posterior, a continuidade não pôde ser observada em razão da sobreposição da imagem do septo nasal.

Nas imagens radiográficas provenientes dos crânios de adultos jovens, espaço entre as margens ósseas da sutura palatina mediana foi identificado no segmento anterior e início do médio nos exemplares H-2.1 e H-2.3. No exemplar H-2.2 as margens ósseas estavam muito próximas nos segmento anterior e palatino médio da sutura palatina mediana. A radiopacidade das margens ósseas era mais intensa neste grupo do que no grupo de crianças. No segmento palatino posterior destes exemplares, a sobreposição da imagem de outras estruturas impediu a análise.

Nas imagens radiográficas provenientes dos crânios de adultos observou-se uma linha radiopaca no trajeto da sutura palatina mediana, sem espaço radiolúcido entre as margens ósseas da sutura

Tabela 3 - Escores atribuídos aos graus de ossificação observados macroscopicamente na sutura palatina mediana em crânios humanos do grupo de adultos jovens.

\begin{tabular}{c|c|c|c|}
\hline Grupo & \multicolumn{3}{|c|}{} \\
\hline Exemplares & 2.1 & 2.2 & 2.3 \\
\hline Escores & 2 & 0 & 1 \\
\hline
\end{tabular}

\begin{tabular}{|c|c|c|c|c|c|c|c|c|c|c|c|c|c|}
\hline Grupo & \multicolumn{13}{|c|}{$\mathrm{H}-3$} \\
\hline Exemplares & 3.1 & 3.2 & 3.3 & 3.4 & 3.5 & 3.6 & 3.7 & 3.8 & 3.9 & 3.10 & 3.11 & 3.12 & 3.13 \\
\hline Escores & 3 & 3 & 3 & 0 & 3 & 0 & 3 & 3 & 0 & 0 & 0 & 3 & 1 \\
\hline
\end{tabular}

\begin{tabular}{|c|c|c|c|c|c|c|c|c|c|}
\hline Grupo & \multicolumn{9}{|c|}{$\mathrm{H}-4$} \\
\hline Exemplares & 4.1 & 4.2 & 4.3 & 4.4 & 4.5 & 4.6 & 4.7 & 4.8 & 4.9 \\
\hline Escores & 3 & 3 & 3 & 3 & 3 & 3 & 3 & 3 & 0 \\
\hline
\end{tabular}


palatina mediana, nos exemplares H-3.2 e H-3.5. Em imagens provenientes de outros exemplares havia a presença de espaço radiolúcido entre as margens ósseas no segmento anterior $(\mathrm{H}-3.3, \mathrm{H}-$ 3.4, H-3.7 e H-3.8) e palatino médio (H-3.2, H3.6, H-3.10, H-3.11, H-3.12 e H-3.13). A análise do segmento palatino posterior foi dificultada pela sobreposição da imagem do septo nasal ósseo. No exemplar H-3.9, o espaço linear radiolúcido foi observado em toda a extensão da sutura, divergindo em direção ao bordo posterior do palato duro.

As radiografias provenientes dos exemplares $\mathrm{H}$ 4.4 e H-4.5 do grupo de idosos foram acidentalmente danificadas impossibilitando sua análise. Este fato não comprometeu a identificação e interpretação dos resultados deste grupo. Nas imagens radiográficas provenientes dos crânios de idosos, a imagem linear radiolúcida entre as margens ósseas da sutura foi observada nos seguimento anterior $(\mathrm{H}-4.1 \mathrm{e}$ H-4.2) e palatino médio (H-4.6 e H-4.8) de alguns exemplares. No exemplar H-4.2, a imagem do septo nasal ósseo estava desviada permitindo observar uma linha radiolúcida delicada na extensão do segmento palatino médio e posterior. Nos exemplar H-4.3 e H-4.9, a imagem da região da linha média sugeria sinostose da sutura palatina mediana em toda sua extensão. Apenas uma tênue linha radiopaca na extensão antero-posterior na linha sagital mediana pôde ser identificada, compatível com a imagem do septo nasal ósseo. Uma imagem linear radiopaca foi acompanhada nos segmentos anterior e médio, no exemplar H-4.7. Também neste grupo, a imagem sobreposta do septo nasal ósseo comprometeu a análise do segmento palatino posterior.

\section{DISCUSSÃO}

A análise macroscópica, realizada nos crânios, permitiu uma visão tridimensional do palato duro, mais especificamente da área correspondente à sutura palatina mediana. Foi identificada a estrutura macroscópica das pontes de ossificação na sutura e o sentido de progressão da ossificação. Desta avaliação, foi possível aferir o grau de ossificação na sutura palatina mediana e inferir a provável razão para a ossificação da sutura iniciar-se pelo segmento posterior, localizado na extremidade livre do palato duro. As suturas cranianas, consideradas estruturas osteogênicas promotoras das adequações locais de crescimento, evoluem gradualmente para a sinostose. A explicação para a deposição óssea que diminui a fenda virtual da sutura ao longo do tempo, seria a mecanotransdução da tradução de estímulos mecânicos gerados pela atividade motora em eventos biológicos, determinando a osteogênese ${ }^{5,17}$. Em níveis ligeiramente maiores que em situações de normalidade homeostática, as citocinas, fatores de crescimento e outros mediadores celulares estimulam a neoformação óssea e em níveis elevados, os mesmos mediadores estimulam reabsorção óssea.

Na sutura palatina mediana, a atividade motora do sistema estomatognático determinaria a deposição óssea nas margens da sutura, necessária às adequações dimensionais durante o crescimento e desenvolvimento do complexo facial. A ossificação das suturas e sincondroses temporárias ocorre após o crescimento e desenvolvimento terem estacionado; com a conseqüente neutralização dos estímulos de adequação dimensional e dos mediadores envolvidos na osteogênese. As diferenças temporais notadas neste processo podem ser relacionadas às diferenças de forma e resultantes de força em cada sistema, peculiar a cada indivíduo.

Dentro de uma espécie, o desenvolvimento ontogenético determina indivíduos tanto mais distintos quanto maior for a evolução, número de mutações e cruzamentos raciais. No homem existem tipos faciais diferentes, decorrentes das características étnicas e miscigenação. Este polimorfismo envolve diferença na angulação na base do crânio, inclinação da fronte, na dimensão vertical da cavidade nasal e na curvatura da abóbada palatina, entre outras. Estas características morfológicas são determinadas pela interação da manifestação genética, predominantemente, e do desenvolvimento funcional. A forma e a função estão, igualmente relacionadas no palato. A forma da curvatura pala- 
tina decorre do padrão craniofacial, das atividades reflexas e dos hábitos desenvolvidos pelo sistema estomatognático. Como exemplo deste polimorfismo, observa-se a maior profundidade da abóbada palatina nos padrões dolicofaciais e um palato quase plano em desdentados totais da maxila, quando a condição persiste por longo período.

As forças resultantes da atividade motora no sistema esquelético são um produto do peso pela gravidade, naquele indivíduo, exigindo maior ou menor estrutura óssea. A arquitetura óssea denota a necessidade de resistência mecânica e as linhas de transmissão das forças incidentes no segmento do qual o osso participa. As formas arqueadas e linhas curvas do crânio refletem as trajetórias de distribuição e favorecem a neutralização das forças geradas pelas atividades reflexas do sistema estomatognático, peso e mobilidade do crânio sobre a coluna vertebral. A forma abobadada do palato reflete a incidência e distribuição de forças por esta região.

O segmento palatino posterior da sutura palatina mediana está inserido em uma extremidade livre do teto abobadado da boca. Nos demais segmentos, a transmissão das forças incidentes ocorre pelos pilares maxilares: canino, zigomático-alveolar e ainda pelo complexo ósseo do septo nasal. No segmento palatino posterior, a mecanotransdução estimularia a deposição óssea, em um processo semelhante ao que ocorre em outros esteios ósseos do crânio: glabela, protuberância occipital externa e mento, entre outros. Nos esteios, a freqüência com que as forças incidem e a concentração de forças, exigem a deposição de maior quantidade de osso, determinando um aumento de suporte, um reforço, resultando em relevo na estrutura do osso.

O grau de ossificação na sutura palatina mediana observado neste trabalho variou, tendo uma tendência a aumentar com a idade. Observou-se sinostose da sutura em três exemplares do grupo de adulto e um exemplar do grupo de idosos com grau 0 quanto à ossificação. A região inicial de ossificação, mais freqüentemente observada, ocorreu no segmento palatino posterior, de acordo com a descrição pré- via de outros autores ${ }^{12,15,16}$. Alguns estudos tentaram relacionar a ossificação nas suturas palatinas com a idade cronológica ${ }^{12,13,16}$. Mann et al. ${ }^{13}$ consideraram que os crânios que apresentavam a sutura intermaxilar "patente" teriam menos de 12 anos. Quando o segmento palatino posterior da sutura palatina mediana estava totalmente ossificado, o indivíduo teria mais de 26 anos. A sutura totalmente ossificada foi identificada em indivíduos acima de 50 anos.

Alguns autores julgaram a imagem radiográfica da sutura palatina mediana de humano em tomada oclusal total da maxila suficiente para determinar a idade cronológica $^{16}$. Pelas análises realizadas neste presente trabalho, acredita-se que esta metodologia não seja apropriada para esta finalidade. A proximidade das margens da sutura na imagem radiográfica, não se relacionou com grau de ossificação na sutura, observado macroscopicamente. A sobreposição da imagem do septo nasal sobre os segmentos palatinos médio e posterior da sutura limitou ainda mais esta análise.

Nas imagens radiográficas da sutura palatina mediana, obtidas pela técnica Oclusal Total da Maxila com modificação na posição do filme no eixo horizontal ${ }^{6}$ foi possivel observar a maior proximidade das margens ósseas em partes ou na totalidade do trajeto assim como variações na radiopacidade nas margens ósseas da sutura. A sobreposição das estruturas e o caráter bidimensional das imagens tornaram temerosa a quantificação da ossificação no trajeto da sutura. Nem mesmo no momento de tratamento das imagens, ao variar os tons claros e escuros e aumentando o contraste foi possivel relacionar, com segurança, dados da imagem radiográfica como a radiopacidade na extensão da sutura à extensão de ossificação, previamente identificada macroscopicamente.

Interessante observar que nos exemplares do grupo de idosos, algumas linhas sagitais medianas apresentavam uma imagem radiopaca linear muito tênue, às vezes descontínua. $\mathrm{A}$ radiopacidade determinada por sobreposição da imagem da margem óssea, esmaecia. Esta imagem sugeriu que a sinostose determinaria remodelação das margens ósseas da sutura. 
De acordo com o sentido de ossificação da sutura, parece apropriado relacionar o grau maturidade óssea com a morfologia da disjunção em Radiografias Oclusais Totais da maxila. Foi demonstrada uma tendência à forma triangular nos indivíduos mais maduros, e uma tendência ao paralelismo das margens ósseas em indivíduos mais jovens ${ }^{18}$. A divergência das margens ósseas, conferindo o aspecto de "V", com o vértice no segmento posterior poderia ser relacionado com o sentido ântero-posterior do processo de ossificação na sutura palatina mediana e amadurecimento das suturas faciais na extensão dos pilares posteriores: zigomáticos e pterigoideus. O complexo ósseo facial da região mais anterior oferece menor resistência à disjunção do que a região posterior do palato, contínuo com a base do crânio e restrito entre os pilares zigomáticos e pterigoideus. Haveria, ainda, amortecimento de forças na sutura palatina transversa.

Esta análise poderia colaborar com a resposta ao questionamento do ganho esquelético transversal real do procedimento de expansão palatina, nos casos de sucesso do procedimento. Quanto maior fosse a maturidade esquelética, maior tendência à forma triangular na obtenção da disjunção, indicativa de maior resistência das junções ósseas da base do crânio; do segmento posterior da sutura palatina mediana, quando ossificado e do amadurecimento das suturas faciais, no trajeto dos pilares posteriores. Nestes casos, a tensigridade do sistema esquelético mais maduro dificultaria a manutenção dos resultados e haveria mais "recidivas". As alterações verticais induzidas pela expansão rápida da maxila são temporárias ${ }^{7}$ enquanto as alterações transversais estão sujeitas à estabilização do sistema e tanto mais suscetíveis quanto maior for a maturidade óssea do esqueleto facial.

\section{CONCLUSÕES}

1) A sutura palatina mediana no homem ossificase especialmente a partir da fase adulta, estabelecendo pontes de ossificação entre as margens ósseas;

2) A ossificação na sutura palatina mediana no homem inicia-se no segmento palatino posterior e evolui no sentido ântero-posterior;

3) Radiograficamente não foi possível avaliar o grau de ossificação na sutura palatina mediana.

Enviado em: Dezembro de 2002 Revisado e aceito: Janeiro de 2004

\title{
Mid-palatal suture: evaluation of the ossification degree in human skulls
}

\begin{abstract}
Objectivs: To analyze the mid-palatal suture ossification rate on human skulls. Sample: Human skulls (28) divided among four groups according to chronological developmental phases: child, teen-ager, adult and elderly. Material: Maxillary Total Occlusal radiographs from different groups of skulls (28). Digitalized images from Maxillary Total Occlusal radiographs (28). Methods: The presence of ossification bridges on the mid-palatal suture were identified, registered and qualified. The radiographs of the skulls were taken using the Maxillary Total Occlusal technique, modifying the horizontal position of the film. These radiograph images were digitalized and submitted to brightness and contrast adjustments to investigate mid-palatal suture ossification rate. Conclusion: The ossification of mid-palatal suture starts mainly at adult phase and on the posterior segment. The Maxillary Total Occlusal radiographic technique does not provide an adequate image to mid-palatal suture ossification rate identification.
\end{abstract}

Key words: Mid-palatal suture. Rapid maxillary expansion. Inter-maxillary disjunction. Maxillary total occlusal radiograph. 


\section{REFERÊNCIAS}

1. ANGELL, E. H. Treatment of irregularity of the permanent or adult teeth. Dental Cosmos, [S. I.], v. 1, no. 10, p. 641-644, 599-601, May 1860.

2. ARNHOLD, I. J. P. et al. Puberdade: normal, precoce e atrasada. In: ESAJCHENBERG, B. Tratado de endocrinologia clínica. São Paulo: Roca, 1992. p. 255.

3. BELL, R. A. A review of maxillary expansion in relation to rate of expansion and patient's age. Am J Orthod, St. Louis, no. 81, p. 32-37, Jan. 1982.

4. CAPELOZZA FILHO, L. et al. Non-surgically assisted rapid maxillary expansion in adults. Int Adult Orthod Orthognath Surg, Carol Stream, v.11, no.1, p.57-66, 1996

5. CONSOLARO, A. et al. O periósteo e a ortopedia dos maxilares. R Dental Press Ortodon Ortop Facial, Maringá, v. 6, n. 4, p. 77-89, jul./ago. 2001.

6. ENNES, J. et al. Sutura palatina mediana: revelações e sonegações da radiografia oclusal total da maxila. In: JORNADA ODONTOLÓGICA DE BAURU., 15, 2002, Bauru. Anais... Bauru: Faculdade de Odontologia de Bauru, Universidade de São Paulo, 2002. p. 40.

7. GARIB, D. G. Avaliação cefalométrica longitudinal das alterações produzidas pela expansão rápida da maxila. $\mathbf{R}$ Dental Press Ortodon Ortop Facial, Maringa, v. 6, n. 5, p. 17-30, set/out. 2001.

8. GUSTAFSON, G. Age determination on teeth. J Am Dent Assoc, Chicago, p. 41-45, 1950.

9. HAAS, A. J. Rapid expansion of the maxillary dental arch and nasal cavity opening the midpalatal suture. Angle Orthod,
Appleton, v. 31, no. 2, p. 73-80, Apr. 1961

10. HAAS, A. J. Palatal expansion: just the begining of dentofacial orthopedics. Am J Orthod, St. Louis, v. 57, no. 3, p. 219-255, Mar. 1970.

11. HAAS, A. J. Long-term posttreatment evaluation of rapid palatal expansion. Angle Orhtod, Appleton, p. 189-207, July 1980.

12. HASSANALI, J.; MWANIKI, D. Palatal analysis and osteology of the hard palate of Kenyan African skulls. Anat Rec, New York, v. 209, p. 273-280, June 1984.

13. MANN, R. W. et al. Maxillary suture obliteration: a visual method for estimating skeletal age. J Forensic Sci, Chicago, v. 36, no. 3, p. 781-791, May 1991.

14. NORTHWAY, W.; MEADE, J. B. Surgically assisted rapid maxillary expansion: a comparison of technique response, and stability. Angle Orthod, Appleton, v. 67, no. 4, p. 291-305, 1997.

15. PERSSON, M.; THILANDER, B. Palatal suture closure in man from 15 to 35 years of age. Am J Orthod, St. Louis, v. 72, no. 1, p. 42-52, July 1977.

16. REVELO, B.; FISHMAN, L. S. Maturation evaluation of ossification of the midpalatal suture. Am J Orthod Dentofacial Orthop, St. Louis, v. 105, no. 3, p. 288-292, Mar. 1994.

17. YOUNG, S. H.; ENNES, H. S.; MAYER. E. A. Mechanotransduction in colonic smooth muscle cells. J Membr Biol, New York, v. 160 , no. 2 , p. $141-150$, Nov. 1997

18. WERTZ, R. A.; DRESKIN, M. Skeletal and dental changes accompanying rapid midpalatal suture opening. Am J Orthod, St. Louis, v. 58, no. 1, p. 41-66, July 1970.
Endereço para correspondência

Jussara Ennes

Rua Aloisio de Azevedo, 1330 - Apto. 302 B

CEP: 79004-050

Campo Grande - MS

E-mail: jennes@ig.com.br 